\title{
Improvement of biomolecular methods for the identification and typing of Escherichia coli O157:H7 isolated from raw meat
}

\author{
A. Paris • S. Bonardi • C. Bacci • E. Boni • F. Salmi • \\ L. Bassi • F. Brindani
}

Published online: 8 May 2010

(C) Springer Science+Business Media B.V. 2010

\begin{abstract}
The aim of the study was to evaluate the sensitivity of two m-PCR methods for the quantitative determination of E. coli $\mathrm{O} 157: \mathrm{H} 7$ in foodstuffs. Genomic serotyping was carried out on bacterial cultures, and the necessary time was optimized to increase the resolution of the method. Subsequently, artificial contamination trials using meat were conducted to assess method accuracy in foodstuffs and pursue the genetic typing of pathogens. Measurement thresholds were shown to range between $10^{5}$ and $10^{6} \mathrm{CFU} / \mathrm{mL}$, but were reduced by four logarithmic cycles in $80 \%$ of samples. Relative to the meat contamination trials, serotypes were identified after 24 hours, corresponding to $10 \mathrm{CFU} / \mathrm{mL}$ inoculum, with higher rates seen when m-TSB was used for enrichment. Inoculated samples were found to contain three virulence factors (hlyA, eaeA, and stxl).
\end{abstract}

Keywords E. coli VTEC · Genomic serotyping · Multiplex PCR · Virulence factors

\author{
Abbreviations \\ STEC E. coli shiga-like toxin \\ VTEC E. coli verocytotoxin \\ HUS hemolytic uremic syndrome \\ CFU colony forming units \\ EHEC E. coli enterohemorragic
}

\section{Introduction}

In the last decades, Escherichia coli strains producing Shiga-like toxin (STEC) or verocytotoxin (VTEC) have taken on an important epidemiological role as emerging foodborne pathogens. Within the group of E. coli, the E. coli enterohemorragic (EHEC)

\footnotetext{
A. Paris $\cdot$ S. Bonardi $\cdot$ C. Bacci $\cdot$ E. Boni $\cdot$ F. Salmi $\cdot$ L. Bassi $\cdot$ F. Brindani Department of Animal Health, University of Parma, Parma, Italy

C. Bacci $(\bowtie)$

Dipartimento di Salute Animale, Sezione di Ispezione degli Alimenti di Origine Animale, Facoltà di Medicina Veterinaria, Università degli Studi di Parma, via del Taglio 10, Parma 43126, Italy e-mail: cristina.bacci@unipr.it
} 
microorganisms have a primary role. This subgroup includes strains able to produce a hemolysin that induces hemolytic uremic syndrome (HUS) (Levine 1987), a serious enterohemorrhagic disease of the human urinary system. Historically, serotype O157 has been the most investigated, even considering that other serotypes have been involved in several epidemic situations (Caprioli et al. 2001; Beutin 2006). Between 1988 and 2004, an overall number of 344 cases of VTEC infection were reported in Italy.

The surveillance system ENTER-NET has reported 19 cases of EHEC in 2006, identifying the following as the most common E. coli serogroups: O26 (36.8\%), O103 (21.1\%), O157 (21.1\%), and O145 (15.8\%) (ENTER-NET Italia 2005; Galetta et al. 2008). In 2003, the Scientific Veterinary Committee Public Health (SCVPH) highlighted the necessity of improving the sensitivity of detection methods for pathogens that produce verocytotoxin during food-monitoring processes. This improvement will also allow comparable data to be obtained from different member states (SCVPH, 2003).

Well-known isolation and identification procedures in the food industry should yield results in a very short time to avoid sanitary risks and, at the same time, have high sensitivity given the low infectious doses of these pathogens (Willshaw et al. 2001). In this context, biomolecular methods may represent a valuable option or may integrate traditional culture methods that normally require a long time to be performed (Fratamico et al. 1995).

\section{Materials and methods}

Considering all of the above, the sensitivity of two multiplex polymerase chain reaction (m-PCR) techniques were tested for the quantitative determination of E. coli O157:H7 directly from foodstuff matrices. Initially, sensitivity was evaluated without interfering factors from the matrix, and genomic serotyping was carried out from bacterial cultures. Subsequently, the time necessary to lower the limit of detection was determined. Afterwards, meat contamination tests were carried out to determine efficiency under conditions of low contamination, which are still relevant for the transmission of infection. Finally, genomic typing of the pathogens was performed. The study of virulence factors for single strains importantly assigned a different role to the strains at the onset of toxic infectious episodes. These biomolecular investigations regarding sensitivity (10 tests) were performed using an E. coli $\mathrm{O} 157: \mathrm{H} 7$ strain isolated from bovine feces, possessing the $r f b \mathrm{E}_{\mathrm{O} 157}$ and $f l i \mathrm{C}_{\mathrm{H} 7}$ genes. These genes encode, respectively, the $\mathrm{O} 157$ somatic antigen and the $\mathrm{H} 7$ flagellar antigen. Moreover, the pathogen has virulence sequences stx 1 , stx 2 (including its variants), $h l y \mathrm{~A}$, and eaeA, which are linked to the synthesis of verocytotoxins, an enterohemolysin, and an intimin. For this reason, dilutions up to $10^{-8}$ were prepared in Tryptone Soya Broth (TSB, Oxoid) taken from inoculated broth media with an average titer of $2 \times 10^{9} \mathrm{CFU} / \mathrm{mL}$. A quantity of $500 \mu \mathrm{L}$ was taken from every dilution for DNA extraction through a $6 \%$ Cheelex resin (BioRad). Serotyping identification was carried out using an $\mathrm{m}-$ PCR method, according to Wang G et al. (2002) protocol, followed by electrophoresis on an agarose gel $2 \%$.

To directly apply this technique on foodstuff matrices, it became necessary to use a preenrichment phase to reduce false-negative results from contamination levels lower than the limit of detection of the method. Therefore, either the first aliquot, which was negative, or the last aliquot, which was positively serotyped, were subjected to confirmation using a preenrichment phase at $37^{\circ} \mathrm{C}$ in TSB for a short $(6 \mathrm{~h})$ and long $(24 \mathrm{~h})$ time period. A $500 \mu \mathrm{L}$ aliquot was taken from each sample at both incubation times to carry out genomic extraction and amplification using a similar protocol to the one previously described above. 


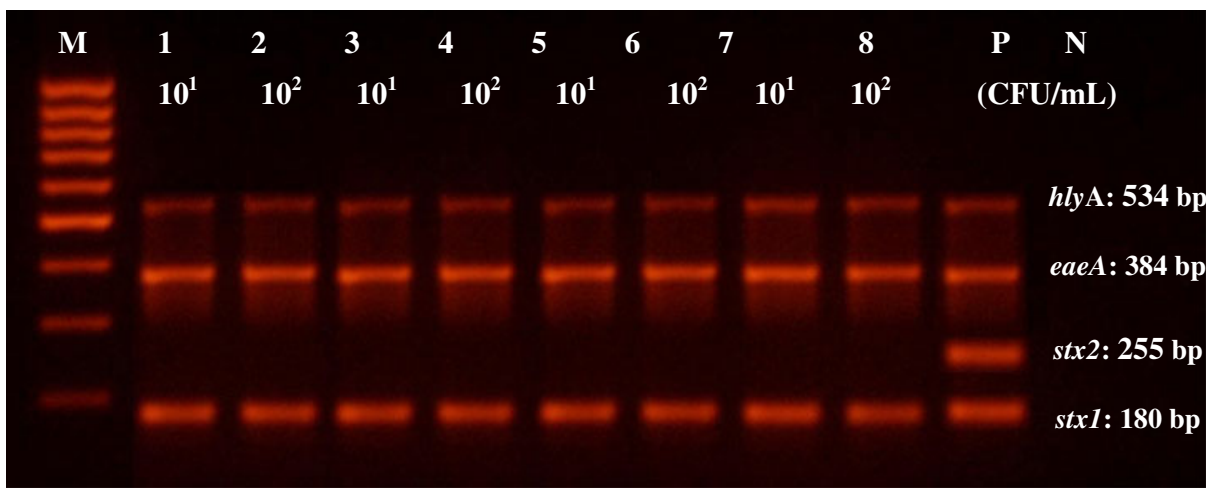

Fig. 1 Electrophoresis of hlyA (534 bp), eaeA (384 bp), stx2 (255 bp), and stxl (180 bp) amplicons carried out by artificial contamination trials on meat matrices after a 24-h incubation. Lanes: M, Mass Ruler ${ }^{\mathrm{TM}}$ DNA Ladder Low Range, (Fermentas); 1-2, test no. 3 in m-TSB; 3-4, test no. 3 in EC broth; 5-6, test no. 4 in $\mathrm{m}-$ TSB; 7-8, test no. 4 in EC broth; P, wild-type strain (VTEC stxl, stx2, hlyA, and eaeA); N, negative control

In meat matrix contamination tests, the verocytotoxic strain used in the first phase with a concentration between $10^{1}$ to $10^{2} \mathrm{CFU} / \mathrm{mL}$ was studied.

The homogenate was prepared using modified TSB (Oxoid) and EC Broth (Oxoid) added to novobiocin and incubated at $37^{\circ} \mathrm{C}$. At respectively 0,6 , and $24 \mathrm{~h}$, three aliquots were taken from each sample for the genomic identification of the serotype to avoid or reduce false-negative results. All positive, extracted samples were then subjected to m-PCR to determine the pathogenic profile (Paton and Paton 1998).

\section{Results}

The results on method sensitivity underlined a rather high detection threshold; in fact, four out of 10 tests yielded positive results for $r f b \mathrm{E}_{\mathrm{O} 157}$ and $f l i \mathrm{C}_{\mathrm{H} 7}$ genes up to $10^{5} \mathrm{CFU} / \mathrm{mL}$ titer, while the others were positive with sensitivity of $10^{6} \mathrm{CFU} / \mathrm{mL}$. As expected, inoculated broth media was positive with longer incubation times, even for very low concentrations $\left(10^{1}-10^{2} \mathrm{CFU} / \mathrm{mL}\right)$. Forty percent of tests had already reached this same sensitivity after just $6 \mathrm{~h}$; method sensitivity was enhanced by $5 \operatorname{logs}$ in $60 \%$ of tests after a $24 \mathrm{~h}$ incubation (Fig. 1, Table 1).

Regarding the contamination tests on meat matrices, all aliquots were negative for both inocula, after either 0 or $6 \mathrm{~h}$ incubation times. After a $24 \mathrm{~h}$ incubation, $80 \%$ of m-TSBinoculated media and $60 \%$ of EC-broth media were positive, even ones with the lowest

Table 1 Sensitivity on TSB without incubation, after short pre-enrichment $\left(\mathrm{T}_{6}\right)$, and enhanced period incubation $\left(\mathrm{T}_{24}\right)$

\begin{tabular}{lllllllllll}
\hline Time & \multicolumn{1}{l}{ (hours) } & \multicolumn{1}{l}{ Detection limit $(\mathrm{CFU} / \mathrm{mL})$} \\
\cline { 2 - 9 } & $10^{9}$ & $10^{8}$ & $10^{7}$ & $10^{6}$ & $10^{5}$ & $10^{4}$ & $10^{3}$ & $10^{2}$ & $10^{1}$ & $10^{0}$ \\
\hline $\mathrm{T}_{0}$ & + & + & + & + & - & - & - & - & - & - \\
$\mathrm{T}_{6}$ & $/$ & $/$ & $/$ & + & + & + & + & + & - & - \\
$\mathrm{T}_{24}$ & $/$ & $/$ & $/$ & + & + & + & + & + & + & - \\
\hline
\end{tabular}


bacterial titer $\left(10^{1} \mathrm{CFU} / \mathrm{mL}\right)$. The samples that were positive by genomic serotyping also possessed three virulence factors (hlyA, eaeA, and stx 1 ), while no stx2 verocytotoxin amplicons were found.

\section{Discussion}

The limit of detection of genomic serotyping was rather high even after $6 \mathrm{~h}$ of incubation. Both $\mathrm{rfbE}_{\mathrm{O} 157}$ and $\mathrm{fliC}_{\mathrm{H} 7}$ amplicons were found at very low contamination rates $\left(10^{1} \mathrm{CFU} / \mathrm{mL}\right)$. The limit of detection was reduced of $4 \log$ in $80 \%$ of cases during short pre-enriching times as reported by others (Vimont et al. 2006). Regarding meat contamination, our results confirmed what has been observed previously. After $24 \mathrm{~h}$ of incubation and even at the lowest inoculation rates, a higher frequency of serotypes was found using m-TSB for enrichment than using EC-broth for isolation of the microorganism. This evidence is even more interesting considering that the inoculated media broth is diluted 10 fold during sampling. The st $x 2$ fragment, which is specific for a contaminating strain, was not found in the homogenates even though Paton's technique involves the application of primers linked to its conserved gene sequences. It could therefore be supposed that the matrix represents an interfering or inhibitory factor to sequence amplification. Information concerning strain specificity and virulence in the food sample could be obtained in a one day with optimization of analysis using m-PCR methods.

\section{References}

Beutin L (2006) Emerging enterohemorrhagic Escherichia coli, causes and effects of the rise of a human pathogen. Journal Veterinary Medical B 53(7):299-305

Caprioli A, Morabito S, Minelli F, Marziano ML, Gorietti S, Pichiorri T, Tozzi AE (2001) VTEC infections, 1988-2000. Notiziario ISS 14:2-3

ENTER-NET Italia (2005) Surveillance of human infection by verocytotoxin-producing E. coli (VTEC): 1988-2004. http://www.simi.iss.it/enternet/dati

Fratamico PM, Sackitey SK, Wiedmann M, Deng MY (1995) Detection of Escherichia coli O157:H7 by multiplex PCR. J Clin Microbiol 33(8):2188-2191

Galetta P, Dionisi AM, Filetici E, Benedetti I, Arena S, Owczarek S, Lana S, Bella A, Scavia G, Rizzo C, Seyler T, Minelli F, Marziano ML, Graziani C, Ciofi degli Atti M, Caprioli A, Luzzi I (2008) Enter-net: Sorveglianza delle infezioni da patogeni enterici. Isolamenti di Salmonella spp., E. coli produttori di verocitotossina e Campylobacter spp. da infezioni umane e da fonti ambientali in Italia nel 2006. Notiziario dell'Istituto Superiore Sanità 21(5):11-17

Levine MM (1987) Escherichia coli that cause diarrhea-enterotoxigenic, enteropathogenic, enteroinvasive, enterohemorrhagic, and enteroadherent. J Infect Dis 155(3):377-389

Paton AW, Paton JC (1998) Detection and characterization of Shiga toxigenic Escherichia coli by using multiplex PCR assays for $\mathrm{stx}_{1}, \mathrm{stx}_{2}$, eaeA, enterohemorrhagic E. coli hlyA, $\mathrm{rfb}_{\mathrm{O} 111}$, and $\mathrm{rfb}_{\mathrm{O} 157}$. J Clin Microbiol 36(2):598-602

SCVPH (Scientific Committee on Veterinary measures relating to Public Health) (2003) Verotoxigenic E. coli (VTEC) in foodstuffs adopted on 21-22 January 2003. http://ec.europa.eu/food/fs/sc/scv/outcome en.html

Vimont A, Vernozy-Rozand C, Delignette-Muller ML (2006) Isolation of E. coli O157:H7 and non-O157 STEC in different matrices: review of the most commonly used enrichment protocols. Lett Appl Microbiol 42:102-108

Wang G, Clark CG, Rodgers FG (2002) Detection in Escherichia coli of the genes encoding the major virulence factors, the genes defining the O157:H7 serotype, and the components of the type 2 Shiga toxin family by multiplex-PCR. J Clin Microbiol 40(10):3613-3619

Willshaw GA, Cheasty T, Smith HR, O'Brien SJ, Adak GK (2001) Verocytotoxin-producing Escherichia coli (VTEC) O157 and other VTEC from human infections in England and Wales: 1995 to 1998. J Med Microbiol 50:135-142 